Revista Iberoamericana, Vol. LXXXIII, Núm. 258, Enero-Marzo 2017, 31-39

\title{
INTERSECCIONALIDAD Y POLIFONÍA. PARA UNA APROXIMACIÓN A LA NARRATIVA DE LUIS NEGRÓN
}

POR

Jorge JoAquín Locane

Los premios, las reseñas celebratorias, las traducciones, las sucesivas reediciones y una prometida transposición al cine de Mundo cruel, de Luis Negrón, curiosamente no han logrado hasta el momento despertar mayor interés entre la crítica académica. Me voy a permitir, por esta razón, una introducción algo abusiva del objeto que me interesa abordar en este trabajo.

Nueve breves relatos componen este libro que de algún modo, por su tendencia a lo "menor" -si se me permite la terminología de Gilles Deleuze-, busca escabullirse y pasar desapercibido: en ninguna de sus ediciones excede las cien páginas. Después de haber aparecido cinco veces en cuidadas editoriales autogestionadas del Caribe y Centroamérica (La Secta de los Perros, 2010; Agentes Catalíticos, 2010, 2011; Germinal, 2012; Ediciones de a Poco, 2013), Mundo cruel comienza a abrirse paso exitosamente en el mundo angloparlante gracias a la edición (2013) de la no menos prestigiosa Seven Stories Press de Nueva York y al trabajo de una traductora con tanta trayectoria y reconocimiento como Suzanne Jill Levine, con lo cual el volumen pasa a insertarse en una genealogía que incluye nombres de enorme valor simbólico para la literatura en general y para la considerada gay en particular como el de Manuel Puig o Severo Sarduy. A esta primera traducción, hay que agregarle una al portugués, aún no publicada, y una al alemán del cuento "Junito" aparecida en la quinta edición (2014) de la revista alba. lateinamerika lesen.

En lo que respecta a distinciones, en el 2010 Mundo cruel recibió una mención de honor en la categoría cuento otorgada por el PEN Club de Puerto Rico y, además, fue destacado como uno de los diez mejores libros del año por el diario El Nuevo Día. Más recientemente, ya en el corriente año, Mundo cruel acaba de recibir el importante Lammy, el Premio Literario Lambda, al mejor trabajo de ficción publicado en el 2013. Este premio distingue desde 1989 las propuestas consideradas de mayor valor de la literatura LGBT publicada en los Estados Unidos, y se inserta dentro del proyecto más 
amplio de asignarle visibilidad y reconocimiento social a los grupos que toman distancia de la norma heterosexual sin que por ello estén dispuestos a resignar derechos civiles. Como añadido, puedo destacar que el Lammy a este trabajo inaugural de Negrón es el primero en los veinticinco años de historia del premio que recibe un texto no redactado originalmente en inglés, es decir, el primero concedido a una traducción, de tal modo que perfectamente se podría especular que la intervención de Suzanne Jill Levine ha actuado como factor considerable.

Luis Negrón, por su parte, bien podría ser presentado como un escritor "tardío", ya que debuta con un volumen de relatos breves recién a los cuarenta años. Pero también se podría proponer que llega a la escritura - una que deberíamos definir en términos restringidos- como un modo de activismo cultural en principio en favor del empoderamiento de subjetividades no reguladas por la norma sexual dominante. En este sentido, Negrón escribe con un fin específico, conducido por un motivo que lo involucra como sujeto definido por rasgos particulares, y no simplemente por mero ejercicio estético. Antes de publicar Mundo cruel, dio a conocer algunos cuentos en volúmenes colectivos de narrativa queer, entre ellas en una que merece mención especial por su carácter ambicioso: Los otros cuerpos. Antología de temática gay, lésbica y queer desde Puerto Rico y su diáspora (2007), de la que, junto a David Caleb Acevedo y Moisés Agosto Rosario, también fue editor. A continuación participó del Colectivo Literario HomoerÓtica, una plataforma de promoción de la literatura LGBT en Puerto Rico que, a su vez, desembocó en diversos proyectos literarios individuales marcados siempre por el distanciamiento de la norma heterosexual. ${ }^{1}$ Con estas referencias lo que estoy proponiendo es que se lea Mundo cruel en el marco más amplio de un corpus literario colectivo e individual emergente, pero con señas de que se halla en proceso de consolidación. Ya a distancia de relatos fundacionales como “¡Jum!” (1966), de Luis Rafael Sánchez, o de la arriesgada producción de un Manuel Ramos Otero, Mundo cruel surge en un contexto en el que un grupo de escritoras y escritores puertorriqueños ha tomado conciencia de sí y decidido enunciar y enunciarse desde hace algunos años a partir de la diferencia exhibida sin solapamientos. A este colectivo autoconsciente se podrían adscribir, entre otras y otros y además de Luis Negrón, figuras destacadas como Mayra Santos-Febres, Yolanda Arroyo Pizarro, David Caleb Acevedo, Karen Sevilla y, por su residencia en Puerto Rico, acaso también Rita Indiana.

En su estudio sobre literaturas homosexuales latinoamericanas, El deseo, enorme cicatriz luminosa (2004), Daniel Balderston sugiere que durante largo tiempo la crítica ha decidido ignorar rastros de deseo homoerótico en la literatura vernácula. Así lo presenta Jorge Quiroga en el "Prólogo" al estudio: “La mascarada crítica ha optado más bien por no ver lo visible, o en seleccionar los detalles necesarios para que lo visible

1 Para una historia del colectivo HomoerÓtica, véase Agosto Rosario. 
no se vea, como sucede en los relatos de Borges donde 'se sugiere la posibilidad del deseo homoerótico y a la vez se horra tal sugestión"” (14). Este esfuerzo crítico iba, a su vez, de la mano de una literatura que dado el caso se pronunciaba desde el reparo del closet. No obstante, Balderston identifica una instancia bisagra en la que al menos una zona de la literatura prefiere abandonar el silencio o el mensaje críptico para sacar a relucir abiertamente su veta homosexual. En palabras de Balderston:

Entonces se puede decir que la ruptura fundamental en el tratamiento de la temática homosexual en América Latina se produce con este artículo de Piñera [uno aparecido en Ciclón] de 1955. Al "revelar" (lo que en inglés se llama ahora outing) a Ballagas como homosexual, al decir que para hablar de "Ballagas en persona" hay que hablar de su homosexualidad atormentada y de la falsa heterosexualidad con que se disfrazaba, Piñera -en contra de los origenistas, y sobre todo, de Lezama y Vitier- abre el camino para que quince años más tarde varios escritores -en Cuba, Antón Arrufat y Reinaldo Arenas, y en el resto del continente, Luis Zapata, Manuel Ramos Otero, Néstor Perlongher, Darcy Penteado, Joao Silvério Trevisan- asuman con naturalidad su identidad homosexual y aborden esa temática sin los secretos laberínticos de las generaciones anteriores. (23)

Esta observación -si es que le queremos dar crédito-, junto con el contexto específico que reconstruí anteriormente, permite pensar que los cuentos de Luis Negrón ya no admiten lecturas en clave de victimización o denuncia de la condición de las subjetividades homosexuales -las que, ciertamente, fueron perdiendo en estigmatización a medida que la literatura, junto a otros discursos, les iba asignando una relativa legitimidad social y aceptación-, sino que están proponiendo otro modo de abordarlas. La narrativa de Negrón, en breve, ya no necesita - ni pretende- darle visibilidad a una condición que en su momento fue construida como abyecta, sino antes dar cuenta de las dispersiones internas, de una diversidad constitutiva que por mucho tiempo ha resultado, acaso ideológicamente, soslayada.

\section{II}

Si pensamos que el título inscripto en una portada opera como un marco destinado a orientar orgánicamente la lectura general del libro que introduce, en el caso de Mundo cruel nos hallamos ante uno que en apariencia puede resultar paradójico. El cuento que le da título al volumen, el último de la serie, presenta un universo cultural donde la homofobia ha sido dejada atrás y la sociedad en su conjunto aceptado su diversidad inherente. Pachi y José A., una pareja gay, se despiertan, emprenden su rutina diaria $\mathrm{y}$ advierten que para su asombro la realidad ha cambiado -al menos en un aspecto particularmente sensible para ellos-por completo: ya no hay rastros de discriminación por orientación sexual: 
Ya en la Land Rover [Pachi] prendió la radio y en todas las emisoras, hasta en las evangélicas, se estaba haciendo un llamado a ponerle fin a la homofobia. Es más, en plena Ponce De León estaban subiendo un billboard con la foto de una pareja de lesbianas con dos nenas negritas que leía: el odio no cabe en el calor de un hogar; vivamos nuestra diversidad. / Pachi miró alarmado y vio a un policía en draga y la gente como si nada. Vio unos chamaquitos cogidos de mano y la gente como si nada. El terror lo embargó. $(61)^{2}$

Más aún, la aceptación ha calado tan profundo en este universo ficcional que el activismo queer ya no encuentra razón de ser. Hacia el fin del relato, "José A. y Pachi se fueron a una esquina y allí se encontraron con unos activistas furiosas y furiosos porque ni a ellas ni a ellos nadie les daba crédito por el fin de la homofobia. 'Deberían hacer un anuncio, dándonos las gracias', decían" (63).

Dado que de este cuento toma prestado su nombre el volumen completo, propongo que este mundo de una aceptación extendida sea entendido como la macroestructura en la que hay que ubicar las micronarraciones, las evidencias casuísticas -podríamos decir-, que conforman el libro. En cada uno de estos casos específicos, a su vez, vamos a observar que, si la opción homosexual no es dominante, al menos ha logrado salir de su invisibilidad y presentarse abiertamente como extendida. Todos los relatos escenifican, pues, algún tipo de experiencia homoerótica, como si la "desviación" fuera en realidad la norma. Las "mamás preocupadas" que conversan en el cuento "Muchos. O de como a veces la lengua es bruja" no dejan de advertir esa propagación y destape: “¡Ay, Virgen! ¿Son muchos, verdad? Mira, se me paran los pelos, y eso que no nos faltan las mujeres" dice la "mamá preocupada también" (46). Y para concluir el relato, un irónico narrador heterodiegético agrega: "Las vemos a lo lejos y podemos apreciar a Santurce repleto de esa rica amenaza que perturba a las preocupadísimas y alarmadas madres. Por lo que se ve, no es para menos" (47).

Ahora bien, si este es el gran escenario que construye Mundo cruel, en los casos específicos, al recorrer cada uno de los cuentos, el lector se enfrenta a un repertorio de retratos y escenas que como resultado final arroja un interrogante sobre la homogeneidad de la comunidad protagónica, es decir, finalmente lo que se impone es el carácter heterogéneo, disperso, de eso que a priori puede ser entendido como una identidad colectiva sin fisuras. Resulta llamativo que en tan pocas páginas Negrón haya logrado poner en escena un repertorio tan vasto. Voy a concentrarme, por esta razón, únicamente en algunos ejemplos que considero destacables.

El punto del que propongo partir es del que todos los personajes que habitan este mundo cruel de Luis Negrón lidian directa o indirectamente con el apartamiento de la norma heterosexual, pero no todos de la misma manera ni bajo las mismas condiciones.

Todas las citas de Mundo cruel pertenecen a la edición aparecida en Germinal en 2012. 
En "El vampiro de Moca", un narrador en primera persona renta selectivamente un estudio en la parte trasera de su casa con el fin de favorecer encuentros sexuales con jóvenes y atractivos inquilinos. Es propietario, de un pasar aceptable, y hace uso de esa condición como para satisfacer su deseo homoerótico. En un momento recibe la llamada de un chico interesado en alquilar el estudio que a él le resulta especialmente atractivo, con lo que se ve conducido a activar sus mejores recursos: "llamé enfermo al trabajo por segundo día consecutivo y lo invité a Plaza para comprarle lo que le hiciera falta" (20). Y más adelante, cuando su operación de conquista fracasa, va a desviar su atención en un tour de consumo: "Aproveché y fui al MAC y al MAPR, a Bellas Artes y a ver todas las películas que ponían en Fine Arts y en el Metro, menos la de Mel Gibson, a quien no soporto por homofóbico" (21).

En "LaEdwin" una conversación telefónica gira en torno al conflicto experimentado por Edwin, "la que se cree hombre", al resistirse a asumir su homosexualidad. Este personaje, estudiante universitario, inicia una relación inestable con un compañero con quien comparte noches de poesía, visitas a galerías y marchas de protesta. Finalmente la relación fracasa y el narrador en primera persona informa en su registro barrial que "La Edwin, con tanta universidad, se dedicó a lo que nos dedicamos casi todas las primerizas, a sufrir..." (30).

En "Botella" el narrador protagonista es un bugarrón, un personaje que sobrevive mediante el cobro por servicios sexuales a homosexuales, gracias a lo cual interactúa con personajes pertenecientes a diferentes zonas socioculturales. Se ve involucrado en un asesinato y busca refugio momentáneamente en la casa de un cliente, un profesor universitario: "Me abre y me dice que huelo a cloro y yo me invento que estaba en una piscina pido que me deje bañar y me deja. Se mete al baño conmigo porque dice que yo le robo si me deja solo y es verdad porque yo le robé unos CD que nadie me quiso comprar, porque eran raros" (38-39).

Este entrecruce de sectores sociales se vuelve a repetir de manera más desarrollada en "El Jardín". Una pareja gay comparte la suntuosa casa de uno de ellos, infectado del virus del SIDA, durante los que se pronostica que sean los últimos días de su vida. Su compañero afectivo y sexual actúa de narrador:

Estábamos en el patio al que Sharon [la hermana de su pareja] y Willie [su pareja] llamaban “jardín", como en el cine, testimonio de su pertenencia a una familia académica. Sus abuelos y abuelas habían enseñado en la universidad. Sus padres habían tenido la oportunidad de estudiar en España y habían regresado a dar clases en el campus riopedrense. Sharon nunca dio clases pero trabajó durante años como asistenta de profesores visitantes. Hablaba cuatro idiomas sin problemas, además de esperanto, la lengua franca soñada por un viejo polaco y que Willie renegaba como un invento sin sentido de palabras que no resonaban a experiencia vivida alguna. Willie se fue a Columbia y regresó con un doctorado en historia del arte con especialización en cine. En su apellido se guardaba un mito universitario, significativo como la Torre misma. (51)

Revista Iberoamericana, Vol. LXXXIII, Núm. 258, Enero-Marzo 2017, 31-39 
En la misma línea argumentativa, cuando el joven narrador siente intriga por los comportamientos sexuales de Sharon, Willie le hace saber "que eso era de mal gusto, recordándome con la advertencia mi origen de casa de bajo costo en parcelas repartidas por el municipio" (52). Y con el afán de poner en evidencia la diferencia ya no de orientación sexual sino la de pertenencia de clase, el narrador afirma que "Quería llevarlo [a Willie] a mi casa en Arroyo para que entendiera porque yo era tan jíbaro. Para que mis padres supieran que él era profesor y de familia" (56). Con lo cual queda patente que si el narrador experimenta un conflicto no es el que origina el apartamiento de la norma heterosexual sino, evidentemente, el que se extrae de la interacción de subjetividades marcadas por su extracción social.

En el último relato, en el que le da título al libro, los dos personajes en torno a los que se desenvuelve el argumento son representativos de una franja social de buen nivel económico; los dos son directivos del sector de negocios y practicantes de un hedonismo consumista que abre paso a la inscripción textual de marcas vinculadas con el actual diseño global hegemónico: Audi, Blackberry, Land Rover, entre otras. $\mathrm{Su}$ pertenencia a este grupo cuyo rasgo central es la alta capacidad de consumo, les permite distinguirse - despreciativamente- de otros sectores. Para mencionar sólo un ejemplo, van a la discoteca de la que son habitués y el narrador informa que "Entraron como pensándolo pero, sin perder el paso y con la nariz respingada, se fueron a una esquina a ver a quién ignorar. No había tanta gente como de costumbre, pero lo peor era que casi todos estaban vestidos de forma casual, por no decir tiraos" (62).

Para concluir este apartado, me gustaría agregar a estas dispersiones signadas por la diferencia de clase las que produce el cruce con las diferentes vertientes del fenómeno de la diáspora. Las subjetividades homosexuales del libro de Negrón, con sus diversos matices, se van a ver, a su vez, aún más complejizadas por los movimientos transnacionales. Muchas veces, además de no coincidir con la norma heterosexual se hallan en tránsito, pero este tránsito tampoco es siempre el mismo ni conducido por las mismas razones.

Uno de los interlocutores de "Junito" está a punto de partir hacia EE.UU. para resguardar a un hijo con aparentes tendencias homosexuales de la discriminación que podría sufrir en Puerto Rico. Hacia allá se dirige como trabajador no calificado y desprovisto de suficientes competencias lingüísticas. Cito:

No, pa Nueva York, no [le dice a su interlocutor]. Es pa Boston que nos vamos. Digo, es más arriba de Boston. Es que mi hermano, Samuel, el mayor, el prietito, trabaja allá en una factoría y están buscando gente. Le habló a la jefa y, pues, pallá voy. Yo me voy alante y después, cuando tenga apaltamento, mando a buscar a la doña y a los nenes. Ella está contenta, los nenes son los que tienen como que miedo por el inglé, vite, pero ya tú verá que rápido lo aprenden... ¿Yo?... Yo hablo el pollito chicken. No, mano, pero me defiendo. A mí, si me hablan suave, yo los puedo seguir pero 
cuando empiezan con el guachulín ese, mano, me pierdo. Pero, vite, en la planta esa hay muchos hispanos, ademá allá to el mundo habla español. Hasta en las tiendas, dice Samuel. (33)

En "Botella” el tránsito también se da hacia EE.UU., igualmente hacia Boston, pero encarnado por un personaje bugarrón, lumpen, buscado por la policía, mientras que en "Muchos" "las mamás preocupadas" comentan otros tipos de flujos poblacionales: el de los dominicanos en Puerto Rico, en referencia a un chico del que sospechan tendencias homosexuales, y el de puertorriqueños de sectores medios en parejas homosexuales que viven en Filadelfia. Cito solo un pasaje en relación con el primer caso. Una de las mamás preocupadas había conversado sobre sus preocupaciones con la madre dominicana del chico sospechoso de homosexualidad. Así le reproduce el episodio a su interlocutora:

MP: Pero óyete el cuento. Me dice la muy malagradecida, que "no se preocupe vecina, que a ese nene se le está criando sin complejos. Moléstele a quien le moleste-hablando duro como para que el marido la escuchara-, que bastante ya tiene con ser hijo de una dominicana y aquí hay mucho prejuicio" y yo le dije: "por eso mismo te lo digo, porque después va a ser peor pa él”. (44-45)

Cierro con una última escena. Después de advertir los cambios de idiosincrasia social ocurridos, el personaje materialista y superficial de "Mundo cruel" decide abandonar Puerto Rico para refugiarse entre sus pares del norte: "En ese momento se prometió que al otro día vendería todo y se iría a Miami. Pues él, José Alfonso Lapís, de los Lapís de Ponce, no se mezclaba con chusma y jamás viviría sin decoro. ¡Jamás!” (64).

Moisés Agosto Rosario ha escrito que Luis Negrón "Nos invita a integrar la diversidad dentro de la diversidad" (116). Creo que precisamente ese es el gran acierto de estos cuentos: dentro de ese espacio identitario, el homosexual, que se ha autoproclamado como divergente en relación con la normativa heterosexual, Negrón traza en líneas gruesas la diferencia interna, una que se define -propongo yo- principalmente por medio de una variable hoy en desuso, esta es, la de clase. Me gustaría, para concluir, retomar dos categorías teóricas para conceptualizar mejor la estrategia narrativa de Luis Negrón. Una del orden textual, otra del sociopolítico.

Fue Mijail Bajtin (1989) quien introdujo el concepto de plurilingüismo o polifonía narrativa para referirse a la convivencia de voces ideológicas en un texto literario. Si es que estas voces interactúan en una suerte de contrapunteo verbal, entonces estamos frente a un tipo de texto dialógico donde las múltiples localizaciones sociales expresan 
su diferencia. No es curioso que los cuentos de Negrón se nutran del habla viva, de la conversación cotidiana, y que por lo tanto tomen la forma de charlas telefónicas, conversaciones casuales en la calle o intercambio de notas escritas redactadas con urgencia. Mundo cruel, desde este punto de vista, se presenta como un foro de debate en torno a una identidad homosexual dispersa, descentrada y poblada de contradicciones. También en este sentido, me permito subrayar, se opone -y cuestiona- a la narrativa monológica de un Jaime Bayly donde un narrador totalitario, siempre anclado en la primera persona del singular, perteneciente a la élite blanca limeña pretende constituirse como vocero único e indiscutido de la identidad gay.

La segunda noción que quiero involucrar es la que han aportado las feministas negras, especialmente Kimberlé Crenshaw (1991), para pensar los cruces de variables diferenciales como género, clase, edad, raza, origen y orientación sexual en función de múltiples niveles de desigualdad y exclusión, me refiero a la de interseccionalidad. Los cuentos de Negrón enfrentan al lector, por un lado, a una realidad en la que los colectivos homosexuales y queers, considerados como bloques unitarios, han conseguido un cierto empoderamiento y reconocimiento social. Yo, personalmente, resido en un país donde nadie se incomoda porque el alcalde de Berlín, Klaus Wowereit, o el exvicecanciller, Guido Westerwelle, se presenten públicamente acompañados por sus parejas masculinas. Con esto no sugiero que todos los derechos antiguamente reservados para los grupos heterosexuales se hayan extendido a los que no se reconocen en el orden normativo - desde ya que ahí hay mucho que recorrer-, pero sí que la estigmatización social se ha ido diluyendo y que razones para una autovictimización no abundan. En un segundo nivel, Mundo cruel obliga a no descuidar las diferencias internas, a pensar que no todo gay es gay de la misma manera ni bajo las mismas condiciones. Que ser gay, dominicano en Puerto Rico y pobre, por ejemplo, debe ser categorizado bajo un rubro aparte del que corresponde al puertorriqueño gay directivo de una multinacional en tránsito hacia Miami. Al respecto, unas palabras de Alexandra Chasin, de su libro Selling Out. The Gay and Lesbian Movement Goes to Market, me parecen concluyentes. En sus términos:

We may be working to enfranchise the gay or lesbian part of ourselves, but if we separate out, even provisionally, that part from other parts, such as our race or class, we will necessarily neglect to work for the freedom and equality of those other parts. And as gay men and lesbians are differently raced, gendered, classed, aged, abled, and even "sexualized," so gay liberation, were it to come, would still leave many gay men and lesbians unfree and unequal. (19)

Al margen de su valor estético, también por esta razón, para que la emancipación siga siendo una pretensión universal, Mundo cruel es sin duda un libro que corresponde celebrar. 


\section{OBRAS CITADAS}

Agosto Rosario, Moisés. "Mapa de la literatura queer, gay, lésbica, trans en el ejercicio literario puertorriqueño del siglo XXI: Literatura en ciernes de identidades múltiples, disidentes, desplazadas e interdependientes". Cartografías queer: sexualidades y activismo LGTB en América Latina. Daniel Balderston y Arturo Matute Castro, comp. Pittsburgh: Instituto Internacional de Literatura Iberoamericana, University of Pittsburgh, 2011. 107-30.

Bajtin, Mijail. "La palabra en la novela". Teoría y estética de la novela. Trabajos de investigación. [1934-1935] Madrid: Taurus, 1989. 77-236.

Balderston, Daniel. El deseo, enorme cicatriz luminosa. Ensayos sobre sexualidades latinoamericanas. Rosario: Beatriz Viterbo, 2004.

Chasin, Alexandra. Selling Out. The Gay and Lesbian Movement goes to Market. New York: Palgrave, 2000.

Crenshaw, Kimberlé. "Mapping the Margins: Intersectionality, Identity Politics, and Violence Against Women of Color." Stanford Law Review 43 (1991): 1241-1299. Negrón, Luis. “Junito”. alba lateinamerika lesen 5 (2014): 60-63. Mundo cruel. Suzanne Jill Levine, trad. New York: Seven Stories Press, 2013. Mundo cruel. San José de Costa Rica: Germinal, 2012.

David Caleb Acevedo, y Moisés Agosto Rosario, eds. Los otros cuerpos. Antología de temática gay, lésbica y queer desde Puerto Rico y su diáspora. San Juan de Puerto Rico: Tiempo Nuevo, 2007.

Quiroga, Jorge. "Prólogo. Impudor y luminosidad: homosexualidad y literatura". Balderston, Daniel. El deseo, enorme cicatriz luminosa. Ensayos sobre sexualidades latinoamericanas. Rosario: Beatriz Viterbo, 2004. 11-16.

Sánchez, Luis Rafael, “¡Jum!”. En cuerpo de camisa. San Juan de Puerto Rico: Editorial Cultural, 1966. 55-60. 
